\title{
Recurrent bleeding after posthemorrhoidectomy caused by factor $V$ deficiency: a case report and review of the literature
}

\author{
Jun Seong Chung, Han Deok Kwak, Jae Kyun Ju \\ Department of Surgery, Chonnam National University Medical School, Gwangju, Korea
}

Congenital factor V (FV) deficiency is a rare hemorrhagic disorder that can cause excessive bleeding during and after surgery in the affected patient. This report is the case of a patient who had FV deficiency with recurrent posthemorrhoidectomy bleeding treated with the hemostatic procedure and fresh frozen plasma (FFP) transfusions. A 45-year-old male patient had previously undergone hemorrhoidectomy for multiple hemorrhoids at a local hospital. Hemorrhoidectomy was successful; however, he was transferred to our hospital for evaluation of the origin of the recurrent posthemorrhoidectomy bleeding and underwent a hemostatic procedure. This bleeding was treated with coagulation using electrocautery, multiple sutures, and FFP transfusion $(1,600 \mathrm{~mL} /$ day) for 7 consecutive days. The patient's plasma FV activity was $23 \%$. Early detection of clotting factor deficiency in patients with hemorrhagic events after surgical treatments may prevent unnecessary procedures such as reoperations and minimize the cost of replacement therapy such as large-volume FFP transfusion.

Keywords: Factor V deficiency; Blood transfusion; Gastrointestinal hemorrhage; Hemorrhoidectomy; Postoperative hemorrhage

\section{INTRODUCTION}

Activated human coagulation factor $\mathrm{V}(\mathrm{FV})$ is an essential nonenzymatic cofactor of the prothrombinase complex, which accelerates the activation of prothrombin to thrombin [1]. Congenital $\mathrm{FV}$ deficiency is a rare autosomal recessive coagulation disorder caused by a homozygotic or heterozygotic mutation of the FV gene. The prevalence of FV deficiency in the general population is approximately 1 in 1,000,000 individuals. Symptomatic FV-deficient patients have less FV activity than asymptomatic FV-deficient patients $[2,3]$. FV deficiency is a rare bleeding disorder with variable bleeding manifestations that do not necessarily correlate

Received: Mar 11, 2021 - Revised: May 20, 2021 - Accepted: May 20, 2021 Correspondence to: Jae Kyun Ju, M.D.

Department of Surgery, Chonnam National University Medical School, 160 Baekseo-ro, Dong-gu, Gwangju 61469, Korea

Tel: +82-62-220-6456, Fax: +82-62-227-1635

E-mail: jkju@jnu.ac.kr

ORCID: https://orcid.org/0000-0003-1605-3310

(C) 2022 The Korean Society of Coloproctology

This is an open-access article distributed under the terms of the Creative Commons Attribution NonCommercial License (https://creativecommons.org/licenses/by-nc/4.0) which permits unrestricted noncommercial use, distribution, and reproduction in any medium, provided the original work is properly cited. with the FV activity level [4]. However, posttraumatic, surgical, and delivery bleeding are common in severe FV deficiency cases. The treatment of bleeding episodes is generally based on factor replacement through fresh frozen plasma (FFP) transfusions with adjunctive pharmacological therapy [5]. Here, we have described a case of a patient with FV deficiency and recurrent posthemorrhoidectomy bleeding who was treated with a hemostatic procedure and FFP transfusions.

\section{CASE REPORT}

This study protocol was reviewed and approved by the Institutional Review Board (IRB) of Chonnam National University Hospital (CNUH-2020-075). Written informed consent was waived by IRB.

A 45-year-old male patient was admitted to a hospital for the surgical treatment of multiple hemorrhoids. This patient was a nonsmoker. He does not have any medical, personal, and family history such as a genetic disorder. Hemorrhoidectomy was performed under regional anesthesia. The surgeon identified the hemorrhoids located at the 3 oclock and 9 o'clock positions, pulled them through the anus, and removed the hemorrhoid tissues us- 


\section{Coloproctology Jun seong chung, et al.}

ing a scalpel and electrocautery. The hemorrhoidectomy sites were sutured. However, severe hematochezia occurred at the hemorrhoidectomy sites. The preoperative coagulation profile test showed a mild prolonged prothrombin time (PT) of 16.1 seconds (normal range, 9.8-13.0 seconds) and prolonged activated partial

Table 1. Laboratory findings including coagulation parameters in this patient

\begin{tabular}{lcc}
\hline Parameter & Result & Reference range \\
\hline PT (sec) & 14.9 & $9.8-13.0$ \\
aPTT (sec) & 49.0 & $26.5-41.0$ \\
PT mixing test & 11.6 & \\
Incubated PT mixing test & 13.1 & \\
aPTT mixing test & 36.9 & \\
Incubated aPTT mixing test & 41.5 & $65-125$ \\
Factor II activity (\%) & 75.0 & $60-140$ \\
Factor V activity (\%) & 23.0 & $50-150$ \\
Factor VIII activity (\%) & 54.1 & $70-120$ \\
Factor X activity (\%) & 63.0 & \\
Factor V Leiden mutation & Negative & $180-350$ \\
Fibrinogen assay (mg/dL) & 182 & $130-450$ \\
Platelets (103/mm ${ }^{3}$ ) & 462 & $72-160$ \\
Protein C activity (\%) & 72.4 & $60-150$ \\
Protein S activity (\%) & 72.8 & $19-31$ \\
\hline Antithrombin III test (mg/dL) & 20.5 & \\
\hline PT, proth Ombin time; aPTT, activated parta &
\end{tabular}

thromboplastin time (aPTT) of 49.7 seconds (normal range, 26.5-41.0 seconds) at local hospital. On postoperative day 4 after the first operation, the coagulation profile test showed further increase in PT (16.3 seconds), aPTT (50.4 seconds), and bleeding time ( 5 minutes; normal range, $\leq 3$ minutes). He underwent suture hemostasis 3 times for bleeding control over 5 days. Subsequently, he was transferred to our hospital for evaluation of the origin of the recurrent posthemorrhoidectomy bleeding and underwent a hemostatic procedure. Vitamin K and tranexamic acid were administered intravenously at admission. Two days after admission, he presented with massive hematochezia at the previous hemorrhoidectomy sites, which was treated with coagulation using electrocautery, multiple sutures, and FFP transfusion (1,600 $\mathrm{mL} /$ day) for 7 consecutive days. Four days after admission, the hematochezia persisted and he experienced cold sweat and dizziness. His hemoglobin level decreased from 10.7 to $7.6 \mathrm{~g} / \mathrm{dL}$. He was intensively transfused with packed red blood cells $(1,440 \mathrm{~mL} /$ day). After 2 weeks of the hemorrhagic event, he did not experience any major bleeding. His laboratory findings and hospital course are summarized in Table 1 and Fig. 1 . This analysis revealed FV deficiency (plasma FV activity, 23\%).

Test for genes associated with FV deficiency was not performed because this patient was lost to follow up. The patient had a mother and 3 sisters who reported no bleeding tendency. However, he had a history of intraoperative bleeding during strabismus surgery in his childhood. The patient was relatively young, and he had no medical history of liver disease, autoimmune disease, vital threatened surgery, certain medications, or malignant cancer.

PT, prothrombin time; aPTT, activated partial thromboplastin time.

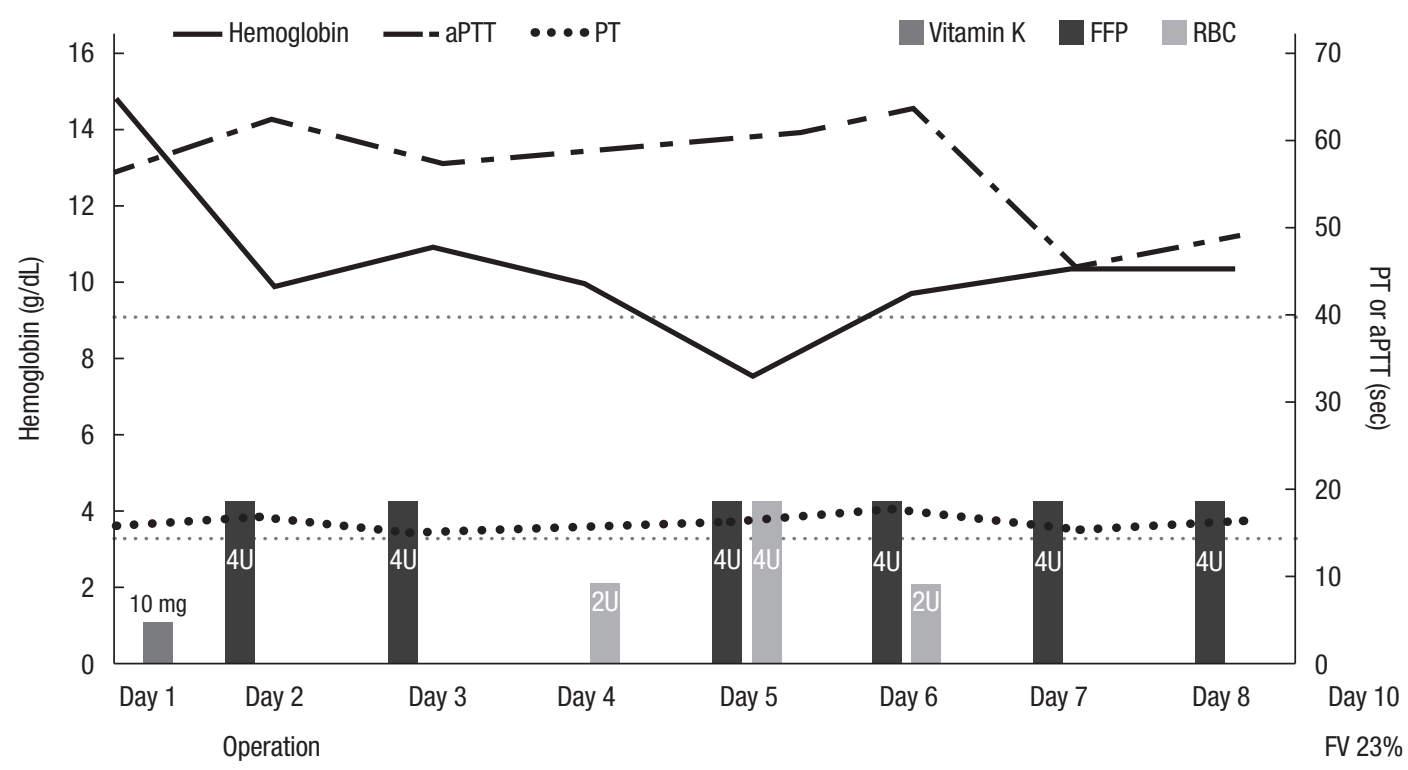

Fig. 1. Hospital course of the patient according to the transfusion. PT, prothrombin time; aPTT, activated partial thromboplastin time; FV, factor V; FFP, fresh frozen plasma; RBC, red blood cell. 
Table 2. Literature review of factor $\mathrm{V}$ deficiency in Korean patients

\begin{tabular}{|c|c|c|c|c|c|c|c|c|c|c|c|}
\hline No. & Sex & $\begin{array}{l}\text { Age } \\
\text { (yr) }\end{array}$ & $\begin{array}{c}\text { PT } \\
\text { (sec) }\end{array}$ & $\begin{array}{l}\text { aPTT } \\
\text { (sec) }\end{array}$ & $\begin{array}{l}\mathrm{FV} \\
(\%)\end{array}$ & Severity & Major bleedingsymptoms & Type & Treatment & Survival & Reference \\
\hline 1 & M & 9 & 36.0 & 110 & 6 & Moderate & Hemarthroses & I & FFP & Alive & [7] \\
\hline 2 & M & $1 \mathrm{mo}$ & 24.9 & $>120$ & 4 & Moderate & Purpuric Pigmentation on skin & । & FFP & Alive & [8] \\
\hline 3 & M & 53 & 18.0 & 49.0 & $<1$ & Severe & CNS bleeding & I & FFP & Alive & [9] \\
\hline 4 & $\mathrm{~F}$ & 28 & 31.3 & 67.8 & 3 & Moderate & Hemoperitoneum & । & FFP & Alive & [10] \\
\hline 5 & M & 73 & 54.1 & 180 & 2 & Moderate & Postoperative bleeding & A & FFP, steroids+IVIG & Dead & [11] \\
\hline 6 & $\mathrm{~F}$ & 63 & 73.1 & 190 & 2 & Moderate & $\begin{array}{l}\text { Retroperitoneal bleeding } \\
\text { (postoperative bleeding) }\end{array}$ & A & $\begin{array}{l}\text { FFP, steroids+ } \\
\text { cyclophosphamide }\end{array}$ & Alive & [12] \\
\hline 7 & $\mathrm{~F}$ & 17 & 17.4 & 50.9 & 16 & Mild & $\begin{array}{l}\text { Postoperative bleeding, } \\
\text { persistent menorrhagia }\end{array}$ & I & FFP & Alive & [13] \\
\hline 8 & M & 24 & 35.7 & 111.7 & 4 & Moderate & No symptoms & I & FFP & Alive & [13] \\
\hline 9 & M & $3 \mathrm{mo}$ & 45.0 & 72.5 & 1 & Moderate & Recurrent epistaxis & I & Local measures & Unknown & [13] \\
\hline 10 & $\mathrm{~F}$ & 49 & 16.7 & 63.4 & 11 & Mild & Postoperative bleeding & I & FFP & Alive & [13] \\
\hline 11 & M & 45 & 14.9 & 49.0 & 23 & Mild & Postoperative bleeding & । & FFP & Alive & Current study \\
\hline
\end{tabular}

PT, prothrombin time; aPTT, activated partial thromboplastin time; FV, factor V; M, male; F, female; I, inherited; FFP, fresh frozen plasma; CNS, central nervous system; A, acquired; IVIG, intravenous immunoglobulins.

\section{DISCUSSION}

FV deficiency is a rare bleeding disorder that can be dangerous of variable bleeding tendency irrespective of the FV activity level. The normal range of plasma FV activity is $76 \%$ to $126 \%$ [6]; however, our patient had an FV activity of $23 \%$. A literature review revealed that only 10 cases of FV deficiency have been reported thus far in Republic of Korea (Table 2) [7-13]. The age of 10 patients ranged from 1 month to 73 years. Male was slightly predominant (male:female $=6: 4$ ). The median of PT and aPTT were 31.3 and 110 seconds, respectively. Most of the patients presented with bleeding symptoms (90\%) and moderate FV deficiency (70\%). FV activity levels ranged from $<1 \%$ to $16 \%$ and all patients were treated mainly with FFP transfusions. A plasma FV activity of $20 \%$ to $25 \%$ is required for effective replacement, with a threshold of $15 \%[4,14]$. It is important to control acute hemorrhagic events by attempting to transfuse FFP for the treatment of FV deficiency. Even in case of gastrointestinal bleeding, after initial stabilization, source control is more likely to resolve the bleeding than exclusive hemorrhagic management. Likewise, suture hemostasis and FFP transfusion were also performed in this case to diminish the frequency and severity of the hemorrhagic episode. Although our patient did not have severe FV-deficiency state, he experienced recurrent and intractable posthemorrhoidectomy bleeding. Our study suggests that the bleeding phenotype can be severe in a FV-deficient patient, even in the presence of low plasma FV levels.

Because the prevalence of FV deficiency is very rare, it is difficult to perform coagulation factor assays in all patients before surgery. However, we would like to suggest situations where addi- tional coagulation factor assays should be performed.

In general, all surgical patients undergo blood tests including PT and aPTT as routine preoperative test. When prolongation of PT or aPTT is observed and there is no specific finding in medical history, such as liver disease, anticoagulation therapy, genetic hemostatic disorder, other medications, performing the coagulation factor assay will be necessary to prevent serious bleeding or abnormal bleeding after surgery and to promptly treat it properly.

Accurate history taking of the patient's medication, surgery, and family history must precede the implementation. In addition, if abnormal findings are observed in the coagulation factor assay, if possible, a genetic test can be performed to distinguish whether it is an acquired or inherited disease, for appropriate treatment.

FV deficiency in Republic of Korea might be ignored because of a lack of understanding; however, there could be more cases of minor unexplained bleeding episodes. Therefore, early detection of clotting factor deficiency in the patient who presented with hemorrhagic events after surgical treatments may prevent unnecessary procedures such as reoperations and minimize the cost of replacement therapy such as large-volume FFP transfusions.

\section{CONFLICTS OF INTEREST}

No potential conflict of interest relevant to this article was reported.

\section{FUNDING}

None. 


\section{ORCID}

Jun Seong Chung, https://orcid.org/0000-0002-9164-8317

Han Deok Kwak, https://orcid.org/0000-0002-0716-6914

Jae Kyun Ju, https://orcid.org/0000-0003-1605-3310

\section{REFERENCES}

1. Monkovic DD, Tracy PB. Activation of human factor V by factor Xa and thrombin. Biochemistry 1990;29:1118-28.

2. Duckers C, Simioni P, Rosing J, Castoldi E. Advances in understanding the bleeding diathesis in factor $\mathrm{V}$ deficiency. Br J Haematol 2009;146:17-26.

3. Acharya SS, Coughlin A, Dimichele DM; North American Rare Bleeding Disorder Study Group. Rare Bleeding Disorder Registry: deficiencies of factors II, V, VII, X, XIII, fibrinogen and dysfibrinogenemias. J Thromb Haemost 2004;2:248-56.

4. Huang JN, Koerper MA. Factor V deficiency: a concise review. Haemophilia 2008;14:1164-9.

5. Asselta R, Peyvandi F. Factor V deficiency. Semin Thromb Hemost 2009;35:382-9.

6. Spiezia L, Radu C, Bulato C, Tognin G, Gavasso S, Barillari G, et al. Platelet factor $\mathrm{V}$ levels in moderate to severe congenital factor V deficiency. Haemophilia 2012;18:e53-5.
7. Song JW, Um MR, Ahn HS, Hong CY. A case of congenital factor V deficiency. J Korean Med Sci 1987;2:179-82.

8. Cho KC, Lee SK, Kim IK, Sung H, Choi CH. A case of combined congenital deficiency of factor V and factor VIII. J Korean Pediatr Soc 1996;39:1162-7.

9. Yoon SG, Cho ST, Park SK, Won JH, Baick SH, Hong DS, et al. A case of coagulation factor $\mathrm{V}$ deficiency complicated with intracranial hemorrhage. Korean J Intern Med 1997;12:80-3.

10. Kim BJ, Lee CH, Kim YH, Cho JS, Park YW. A case of vaginal delivery in woman with congenital factor $\mathrm{V}$ deficiency. Korean J Obstet Gynecol 2002;45:873-7.

11. Kim SY, Kim HK, Kim SW, Cho HI. A case of acquired factor V Inhibitor. Korean J Hematol 2008;43:190-3.

12. Ha SH, Kim JH, Jang SY, Hwang JA, Sohn HJ, Yeon JW. A case of acquired factor $\mathrm{V}$ deficiency treated with corticosteroids and cyclophosphamide. Korean J Med 2012;82:105-9.

13. Park YH, Lim JH, Yi HG, Lee MH, Kim CS. Factor V deficiency in Korean patients: clinical and laboratory features, treatment, and outcome. J Korean Med Sci 2016;31:208-13.

14. Bolton-Maggs PH, Perry DJ, Chalmers EA, Parapia LA, Wilde JT, Williams MD, et al. The rare coagulation disorders--review with guidelines for management from the United Kingdom Haemophilia Centre Doctors' Organisation. Haemophilia 2004;10:593628. 